Mappi ng for est burned area usi ng MOD S dat a in Chi na

\begin{tabular}{|l|l|}
\hline 著者 & Li u Ronggao, Li u Ji yuan, Lu Xi aol i ang, Yan Hou \\
\hline $\begin{array}{l}\text { j our nal or } \\
\text { publ i cat i on ti tl e }\end{array}$ & $\begin{array}{l}\text { Envi r onment al Noni t or i ng I n East Asi a ; Rentet e } \\
\text { Sensi ng and For est s }\end{array}$ \\
\hline page range & $79-84$ \\
\hline year & 2005- 01-01 \\
\hline URL & ht t p: //hdl . handl e. net /2297/6329 \\
\hline
\end{tabular}




\title{
Mapping Forest Burned Area Using MODIS Data in China
}

\author{
Ronggao Liu ${ }^{1 *}$, Jiyuan Liu ${ }^{1}$, Xiaoliang Lv ${ }^{1}, \mathrm{Hou}_{\mathrm{Yan}^{2}}$ \\ ${ }^{1}$ Institute of Geographical Sciences and Natural Resources Research, Chinese Academy of Sciences \\ No.11A, Datun Road, Beijing, 100101 P. R. China \\ ${ }^{2}$ Forest Fire Monitoring Center, Chinese Administration of Forest \\ * Tel: 86-10-64889466; Email: Lronggao@yahoo.com
}

\begin{abstract}
The burned area is an important parameters for modelling the carbon cycles. The remote sensing tenology is a only way to monitor it at large scale region. In general, two temporal vegetation index difference was used to detect the burned area. But this technology is difficult to be applied to large-scale region owing to the BRDF effect, atmospheric contamination, geolocation errors, phenological changes, vegetation regrowth and others. In this paper, a new approach was proposed to detect the burned area using MODIS data, which is based on the vector-change technology, and combines the MODIS 500 and 250 meter resolution bands data to find 250 meter resolution burned area. The method adequately uses the spectral and multi-spatial resolution character of MODIS data that can resist the noise pollution and improve the detection accuracy. The detection results are very corresponding with the visual interpretation under different background. Since the method needs no prior knowledge, it could also be applied in large region scale. Based on this algorithm, the burned area dataset covering all China from 2000 to 2004 were produced.
\end{abstract}

\section{INTRODUCTION}

Land Biomass burning is a major cause of the Earth's land cover conversion. Fires destruct natural ecosystems, deposit ash on the ground that change the ground characteristics which alter the Earth's radiation budget and introduce uncertainties in climate modeling. At the same time, biomass burning can also release land surface carbon stocks to the atmosphere, which affect biosphere-atmosphere interactions and atmospheric composition by emission trace gases and smoke aerosols to atmosphere at regional and global scales $[1,2,3]$. It may be the main source of uncertainties for modeling of global carbon cycle. Accurate and timely accounting of burns is critical for the monitoring of biodiversity and animal habitat, the management of natural resources and the understanding of carbon cycle.

Currently, remote sensing of fires is a well-established technology based on hot spot detection in satellite sensor midand thermal infrared channels. Several global fire products are currently in operational production from NOAA AVHRR [6] and MODIS [5]. A realtime fire monitoring system has also been built in Chinese Administration of Forest in China, which based on AVHRR, MODIS and FY satellite data. In contrast to fire detection, the burned area detection is ongoing research field for large scale, though some global data are available $[4,9]$. In general, the vegetation index, such as
NDVI and the Burned Index difference [11] from two temporal were used to detect the burned area. But this technology is difficult to apply to large scale region because the effect of variations in surface reflectances as a function of sun-target-sensor geometries [8], variations in accuracy of atmospheric correction as function of image acquisition time, variations in geolocation errors, problem of separation of phenological changes from those due to biomass burning, lack of temporal persistence of burns (vegetation re-growth) and others. To alleviate these problems, some complicated methods were designed, including compositing data to reduce threshold sensitivity to bi-directional reflectance effects and residual cloud and atmospheric contamination, application of empirical correction factors to account for phenological changes in vegetation or using only single satellite image. But these technologies are still difficult to process large scale data automatically.

In this paper, we provide a new method to detect the burned area using MODIS data. The method is based on the vector-change technology $[12,13]$, and combines the MODIS 500 meter resolution bands and the 250 meter resolution bands data to find 250 meter resolution burned area. The method adequately uses the spectral character of MODIS data that can resist the noise pollution and improve the detection accuracy. Simultaneously, it uses the 250 resolution bands to find more fine burned area. This method has been used to produce burned area from 2000 to 2004 covering all China, which is very corresponding with the visual interpretation results. Since it needs no background information, the method should also be applied global scale.

\section{METHOD}

If we assume a pixel's two bands $R_{1}$ and $R_{2}$ which values are $\left(\mathrm{R}_{1}\left(\mathrm{t}_{1}\right), \mathrm{R}_{2}\left(\mathrm{t}_{1}\right)\right)$ at time 1 and $\left(\mathrm{R}_{1}\left(\mathrm{t}_{2}\right), \mathrm{R}_{2}\left(\mathrm{t}_{2}\right)\right)$ at time 2 , the change direction angle (A) and distance (D) can be expressed as:

$$
\begin{aligned}
& D=\sqrt{\left(R_{1}\left(t_{2}\right)-R_{1}\left(t_{1}\right)\right)^{2}+\left(R_{2}\left(t_{2}\right)-R_{2}\left(t_{1}\right)\right)^{2}} \\
& A=\arctan \left(\left(R_{1}\left(t_{2}\right)-R_{1}\left(t_{1}\right)\right) /\left(R_{2}\left(t_{2}\right)-R_{2}\left(t_{1}\right)\right)\right.
\end{aligned}
$$


For Red-NIR spectral space, $R_{1}$ can be Red and $R_{2}$ be NIR band. For NIR-MIR spectral space, $R_{1}$ can be NIR and $R_{2}$ be MIR band. The spectral space can be shown in figure 1 as different land cover type. From figure 1(a), we can find that if a pixel is forest (A) at time 1, it may change to a new burned scar (C), old burned scar (B), bare soil (D), or it may be covered by smoke (E) or cloud (F). Though the NDVI $(($ NIR-Red $) /($ NIR + Red $))$ value of new burned scar is nearly same as cloud, the spectral space is very different. So it is difficult to distinguish the atmospheric contamination from burned scar in the vegetation index based detection method, but the vector change method can detect it easily. This determines the vector change of spectral space is more powerful in detection of burned area. For the NIR-MIR space, the new burned scar is sensitive to the spectral indexs ((NIR-MIR)/(NIR+MIR)), but the bare soil and burned area are nearly same value which makes it problematic to determine a pixel to be bare soil or new burned scar. Therefore, combination of the vector change of Red, NIR and MIR is more easy detect the burned scar change from other land cover change.

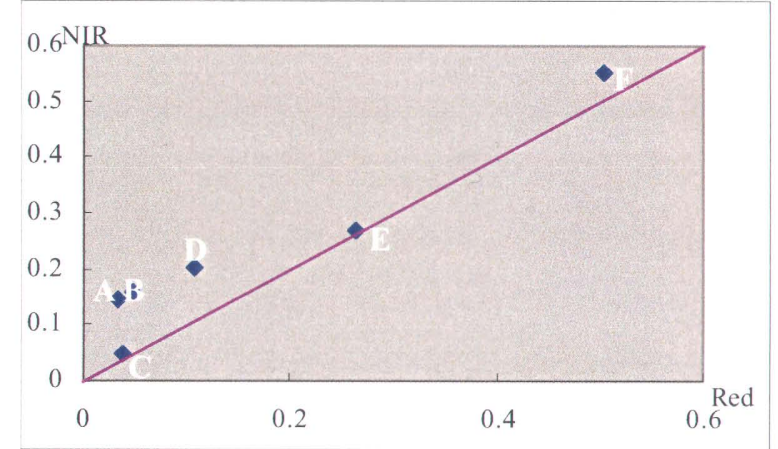

(a)

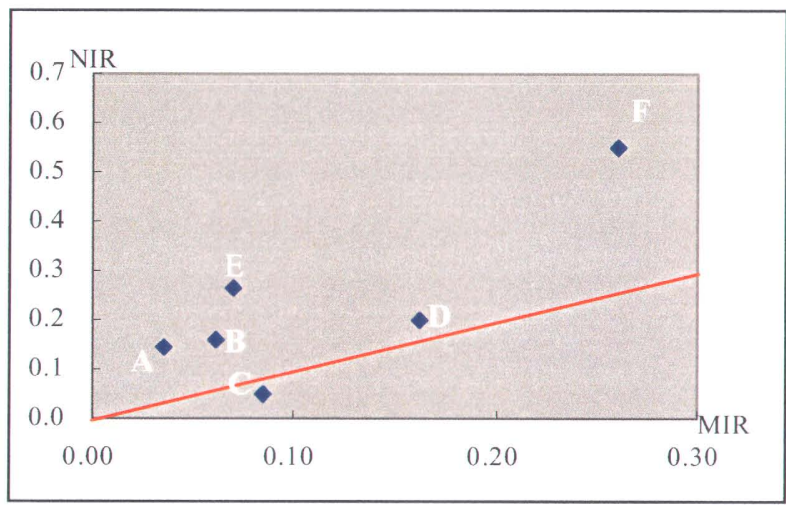

(b)

Fig. 1. The spectral space for different land covers. (a) Red-NIR; (b) NIR-MIR. A is the forest, B is old burned scar, C is new burned scar, D is bare soil, $\mathrm{E}$ is smoke, $\mathrm{F}$ is cloud.

According to the algorithm describing before, the steps to automatically detect burned scar from multi-temporal MODIS data are:

(1) Correction of the atmospheric effect. In many cases, the correction of atmospheric Rayleigh scattering is enough. The aerosol effect correction is helpful for improvement its accuracy for the large aerosol region. The dark objects method is enough owing to the detection area are bounded to forest.

(2) Griding the MODIS level 1B data to projection grid using the its coordinate information;

(3) Composite MODIS data from several days. In order to get the more accurate land surface reflectance information, a comparison of minimum band based multi-temporal compositing method [7] is used, which can keep the burned information and remove the shadow contamination effectively. Consideration of the temporal interpolation may introduce additional error, it is not be utilized to remove the residual cloud in composite data.

(4) Construction the change vector data from composite MODIS data, the output data include change angle and its magnitude.

(5) Classification of the change angle and magnitude data to detection burned scar.

The output burned scar data include $500 \mathrm{~m}$ resolution and $250 \mathrm{~m}$ resolution, which are derived from MODIS $250 \mathrm{~m}$ resolution and $500 \mathrm{~m}$ resolution data respectively. From these data, we can estimate the global China burned area in the specific period.

\section{RESULTS}

The results for the algorithm are shown in figure 2. Fig.2 (a) and (b) are the band 7,2,1 composite image before and after fire respectively. The green regions are the forest and the red regions in fig. 2(b) are the fire scars. Fig. 2 (c) shows that the NDVI-based method is poor in detection the scar. The phenological changes, cloud contamination in post fire data can lead to the NDVI change largely and these changes are uneven in different region. Therefore, the NDVI-based method can't determine the changes of NDVI value at two periods are derived from the burned scar or other factors. The CBI method [11] (fig. 2 (d)) are sensitive the bare soil. It could also mistake phonological change as burned scar. But the CBI approach is better than NDVI-based method in the resistance of cloud and aerosol contamination. Fig. 2(e) shows the vector change method can detect the burned scar and avoid the contamination from aerosol, cloud and phonological change. This method was used to produce the yearly burned area database of global China.

\section{SUMMARY}

A vector change based method for detection of the burned scar from multi-temporal observations was proposed. The results indicate that this method can effectively detect the burned scar. Comparison with NDVI-based and CBI based 
method, this method is more robust for resistance the contamination of cloud, aerosol and other land cover change. This method has been used to produce burned scar data of global China.

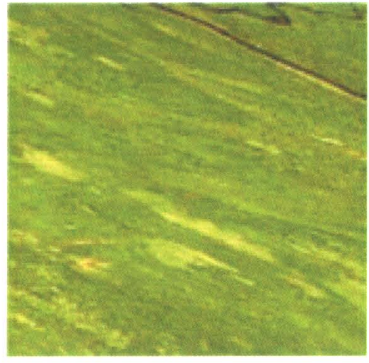

(a)

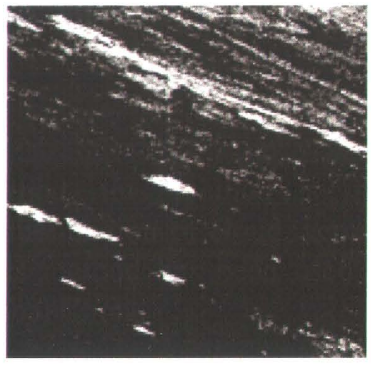

(c)

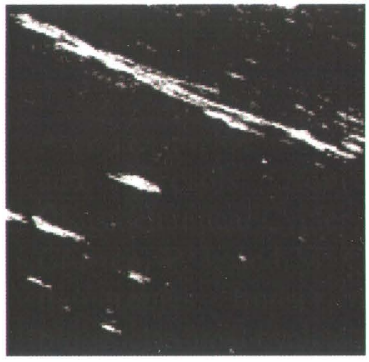

(e)

Fig. 2. The burned scar detection for different algorithm. (a) Before burned color image for band 7, 2, 1; (b) After burned color image for band 7, 2, 1. (c) The NDVI difference based detection result; (d) The CBI different based detection result; (e) The vector change based detection result.

\section{ACKNOWLEDGMENT}

This research was supported in part by the National 973 program (No. 2002CB4125) and National Natural Science Foundation from China (No.40471098, No. 90202002).

\section{REFERENCES}

[1] Andreae, M. O. and P. Merlet, "Emission of trace gases and aerosols from biomass burning", Global Biogeochemical Cycles, 15(4), 955-966, 2001.

[2] Crutzen, P. J. and M. O. Andreae, "Biomass burning in the tropics: Impact on atmospheric chemistry and biogeochemical cycles", Science, 250, 1669-1678, 1990.
[3] Crutzen, P. J., L. E. Heidt, J. P. Krasnec, W. H. Pollock, and W. Seiler, "Biomass burning as a source of atmospheric gases $\mathrm{CO}, \mathrm{H}_{2}, \mathrm{~N}_{2} \mathrm{O}, \mathrm{NO}, \mathrm{CH}_{3} \mathrm{Cl}$, and $\mathrm{COS}^{\prime}$, Nature, 282, 253-256, 1979.

[4] Gregoire, J. M., K. Tansey, and J. M. N. Silva, "The GBA2000 initiative: Developing a global burned area database from SPOT-VEGETATION imagery", International Journal of Remote Sensing, 24(6), 1369-1376, 2003.

[5] Kaufman, Y. J., C. O. Justice, L. Flynn, et al., "Potential global fire monitoring from EOS-MODIS", Journal of Geophysical Research, 103, 32215-32238, 1998.

[6] Li, S., S. Nadon, and J. Cihlar, "Satellite-based detection of Canadian boreal forest fires: Development and application of algorithm," International Journal of Remote Sensing, 21, 3057-3069, 2000.

[7] Liu, R., S. Liang, J. Liu and X. Lv, "A new composite method for multi-temporal remote sensing data", IGARSS05, 2005.

[8] Roy, D. P., P. E. Lewis and C. O. Justice, "Burned area mapping using multi-temporal moderate spatial resolution data --a bi-directional reflectance model-based expectation approach", Remote Sensing of Environment, 83, 263-286, 2002.

[9] Simon, M., S. Plummer, F. Fierens et al., "Burnt area detection at global scale using ATSR-2: The GLOBSCAR products and their qualification", Journal of Geophyscial Research, 109, D14S02, doi:10.1029/ 2003JD003622, 2004.

[10] Tansey, K., et al., "Vegetation burning in the year 2000: global burned area estimates from SPOT VEGETATION data", Journal of Geophysical Research, 109, doi:10,1029/2003JD003598, 2004.

[11] van Wagtendonka, J. W., Ralph R. R, Carl H. K, "Comparison of AVIRIS and Landsat ETM+ detection capabilities for burn severity", Remote Sensing of Environment, 92, 397-408, 2004.

[12] Zhan, X., R. DeFries, J. R. G. Townshend, et al., "The $250 \mathrm{~m}$ global land cover change product from the Moderate Resolution Imaging Spectroradiometer of NASA's Earth Observing System", International Journal of Remote Sensing, 21(6,7), 1433-1460, 2000.

[13] Zhan, X., R.A. Sohlberg, J.R.G. Townshend, et al., "Detection of land cover changes using MODIS $250 \mathrm{~m}$ data", Remote Sensing of Environment, 83, 336-350, 2002 . 